AperTO - Archivio Istituzionale Open Access dell'Università di Torino

\title{
PUBLIC HEALTH MANAGEMENT FACING DISASTER RESPONSE: A BUSINESS PROCESS SIMULATION PERSPECTIVE
}

\section{This is the author's manuscript}

Original Citation:

Availability:

This version is available http://hdl.handle.net/2318/1686326

since 2019-01-09T15:56:03Z

Publisher:

WSC

Terms of use:

Open Access

Anyone can freely access the full text of works made available as "Open Access". Works made available under a Creative Commons license can be used according to the terms and conditions of said license. Use of all other works requires consent of the right holder (author or publisher) if not exempted from copyright protection by the applicable law. 


\title{
PUBLIC HEALTH MANAGEMENT FACING DISASTER RESPONSE: A BUSINESS PROCESS SIMULATION PERSPECTIVE
}

\author{
Emilio Sulis, Antonio Di Leva \\ University of Turin \\ Computer Science Department \\ Corso Svizzera 185 - 10149 Turin, Italy
}

\begin{abstract}
This paper focuses on process analysis and computational simulation to address public health management in case of disaster response. By adopting a Business Process Management perspective, we perform organization modeling and analysis as a management tool by comparing results from agent-based and discrete event simulations. We focus on the consequences of a mass tragedy, exploiting real data from an Emergency Department after a crowd disaster where people were stamped as a consequence of mass panic. Our models consider activities with corresponding durations, resources as well as patients arrivals based on real data. Finally, once models were validated by managers, simulations can be used to provide suggestions as well as to propose different set of responses to disaster stress in emergency management.
\end{abstract}

\section{INTRODUCTION}

Homeland security is a field of study and practice including several facets and meanings (Kahan 2013; Bellavita 2008). In this context, emergency management is one of the core issue, where public sector provides services like assistance for law enforcement, public safety, environmental response and health services facing all kinds of hazards, i.e. terrorism attacks or catastrophes. Consequently, studies on disaster management involve several scientific disciplines, ranging from medicine (Tintinalli et al. 2016) to politics and public policies (Sylves 2014; Birkland 2009). In this work, we focus on the management of disaster to prevent losses from hazards, assuring prompt and appropriate medical assistance to victims in order to achieve rapid and effective recovery. In a typical disaster management cycle of four phases - preparation, response, recovery and mitigation, we particularly deal with first two. Preparedness concerns plans of emergency exercises or training, as well as warning systems. Responses include every efforts to minimize the hazards following a disaster.

In particular, we explore techniques of Business Process Management (BPM) discipline combined with computational simulations, in order to support decision-making and management systems. We stress the relevance of process analysis about public health to estimate and simulate the impact of different configurations (scenario analysis) on health services. The proposed methodological framework is suitable to be applied in public health and medical preparedness to address a wide range of possible emergency scenarios.

Our case study concerns the impact of a crowd disaster to an hospital Emergency Department in Italy. We model healthcare processes to perform different modeling techniques, in order to compare results from the two. The output of business processes simulations can drive managers in arrange and reorganize services by varying the use of resources, by estimating the impact of an increment of arrivals or by changing the sequence of activities.

In the following sections we introduce a review of related works on BPM and simulation studies (section 2), including some applications to disaster management. Section 3 describes our data and method- 
ological framework introducing the case study, the standard notation BPMN 2.0 as well as discrete-event and agent-based modeling with related sets of Key Performance Indicators (KPIs). In section 4 we detail the construction of our two models, while section 5 describes the definition of the scenarios used to specify possible evolutions of the actual business models and their analysis. Finally, we draw some concluding remarks in Section 6.

\section{RELATED WORKS}

Business Process Management (BPM) is a well-established discipline (Dumas et al. 2013) focused on applications to facilitate organizations to identify, describe, analyze, test, monitor and simulate business processes (Van Der Aalst, Wil MP and La Rosa, Marcello and Santoro, Flávia Maria 2016). Several works implements the analysis of the actual situation of organization's processes (As-Is) for re-engineering business processes (To-Be) (Van Der Aalst 2013; Trkman 2010). In this context, computer-based decision support systems (Shang and Seddon 2002) compare the actual and the simulated process indicators in performance analysis (Van der Aalst et al. 2010). The exam of different scenarios (Chang 2016) addresses planning, risk management (Amantea et al. 2018) and decision-making (Di Leva et al. 2017).

Some works adopted a business process perspective to emergency studies. For instance, an adaptive process-management system was defined in (Catarci et al. 2008), while a decision support system provides disaster preparedness in supply chains facilities (Hale and Moberg 2005). In addition, scenario analysis explores the impact of different simulated models (Viswanadham 2018). Disaster management involves the organization of resources and responsibilities to deal with several different aspects of emergencies (Shimada et al. 2012).

Computational simulations are widely applied in healthcare (Tracy et al. 2018; Gunal 2012; Di Leva and Sulis 2017), whereas the importance of simulations for disaster preparedness of Emergency Departments is surveyed in (Gul and Guneri 2015). Agent-based simulations were applied to a wide range of different fields of disaster management, as well as evacuation (Tan et al. 2015), emergency response management with crowd simulation (Shendarkar et al. 2008), natural disasters (Mustapha et al. 2013), terrorism prevention (Li et al. 2015; Bulleit and Drewek 2005). Our work concerns simulation of emergency preparedness activities in addition to emergency exercises which usually involve healthcare workers (Skryabina et al. 2017). The role of modeling and simulation for disaster preparedness is crucial for scenario planning, making modifications as well as what-if trade-off analyses for effective disaster response (Mapar et al. 2012).

\section{DATA AND METHODOLOGY}

We refer to a hospital emergency department (ED) in the province of Turin, a densely populated area in Italy. The department includes typical services such as blood analysis, radiology and imaging tests. ED staff includes 4 doctors, 2 triage nurses, 7 ED nurses and 2 social workers. The total number of patients arrived in 2017 was 46,840, for a daily average of 127 . Most patients arrived by their own and about four hundreds by ambulance. Italian hospitals adopt a four-level Emergency Severity Index (ESI) from 1 (very high) to 4 (very low), which is defined after a series of initial activities, the so-called Triage. A typical weekly trend with a slight decrease over the weekend for each of the four types of ESI patients, is described in Figure 1. 


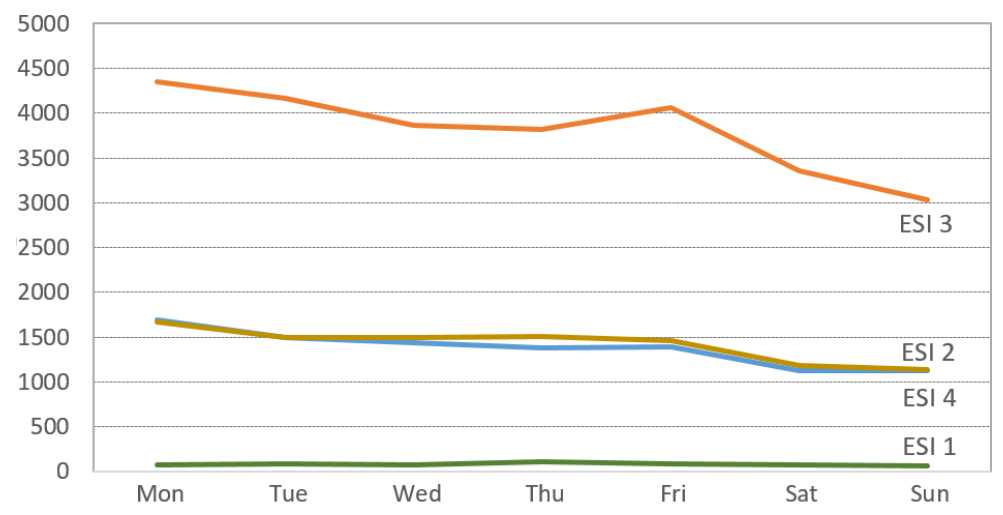

Figure 1: Average arrival of patients by day in our case study, year 2017

Similarly, daily trends follow a typical pattern consisting of two peaks, one in the morning and one in the afternoon. In the following, we describe stampede consequences before to introduce some methodological issues for our two computational simulations.

\subsection{Stampede consequences}

To focus our attention on the management of emergency scenarios in an Hospital ED, we considered the consequences of mass panic involving hundreds of people. A tragic event happened in June 2017, while thousands of fans were watching a live relay of Football in a big place of the city center in Turin, one of the largest Italian cities ${ }^{1}$. Mass panic produced more than 1,500 people hurt and a woman dead when crowds rushed away. Most crush injuries were broken bones, bleeding, severe bruising, lacerations and compartment syndrome.

Hospitals of the province of Turin experienced in late night a large increase of arrivals of such kind of patients. We focus on Orbassano Hospital ED, which experienced a patient increment of 70 percentage points in June 4th, with respect to previous Sunday (May 28th), as described in Table 1.

Table 1: Comparison between patients on Sunday May 28th (a normal day) and June 4th (the day of the crowd disaster)

\begin{tabular}{l|c|c} 
Urgency level & May 28th & June 4th \\
\hline ESI 1 (urgent) & 1 & 6 \\
ESI 2 & 23 & 42 \\
ESI 3 & 80 & 122 \\
ESI 4 (not urgent) & 7 & 18 \\
\hline Total & 111 & 188
\end{tabular}

The number of services (i.e. blood tests, echo-cardiograms, small wound sutures), examinations (X-Ray, CATs, ultrasounds scans) as well as requests of medical advices clearly shows the impact of emergency situation, with a total increment of 55\%. In particular, consequences of stampede increased the number of radiographic examinations $(+111 \%)$, services $(+45 \%)$ and medical advices $(+29 \%)$, as reported in Table 2.

\footnotetext{
${ }^{1}$ Cfr. Stampede at Piazza San Carlo in Turin: http://www.bbc.com/news/world-europe-40147813
} 
Table 2: Comparison between number of services, medical advices and exams the night of the tragedy (June 4th) and a similar normal one (May 28th).

\begin{tabular}{l|ccccc|ccccc|c} 
& \multicolumn{7}{c|}{ May 28th } & \multicolumn{7}{c|}{ June 4th } & \\
\hline Activities - ESI & $\mathbf{4}$ & $\mathbf{3}$ & $\mathbf{2}$ & $\mathbf{1}$ & tot & $\mathbf{4}$ & $\mathbf{3}$ & $\mathbf{2}$ & $\mathbf{1}$ & tot & increment (\%) \\
\hline Examinations & 5 & 56 & 28 & 1 & 90 & 4 & 96 & 75 & 15 & 190 & 111 \\
Medical Advices & 4 & 32 & 15 & 1 & 52 & 3 & 33 & 25 & 6 & 67 & 29 \\
Services & 22 & 240 & 93 & 5 & 360 & 43 & 277 & 176 & 25 & 521 & 45
\end{tabular}

To face such an increase of patients, ED managers quickly decided to increase personnel. In particular, the night of the emergency were called to work 7 physicians, 1 triage nurse, 4 ED nurses as well as 3 OSS. Such elements were considered in our scenario simulations, as described below.

\subsection{Methodological framework}

We modeled activities of ED Department in two different ways, by adopting Discrete-Event Simulation (DES) as well as Agent-Based Modeling (ABM). As our interest here concerns emergency management, we perform simulation considering a warm up period of 6 days (from Monday to Saturday), followed by the day of the tragedy (in such a day we simulate the arrivals of more patients as stated by our real data analysis) and one more day, in order to complete processes execution. In the warm up period, the patient arrivals follow the above mentioned typical trend. This period is necessary to get simulation system into conditions that are typical of normal functioning, before starting to collect results for statistical analysis. The business process analysis includes several Key Performance Indicators: Length of Stay (LOS) is the time between the arrival of a patients to discharge from the ED; Door To Doctor Time (DTDT) is the time difference between arrival of a patient and the time a physician first visit. From a Process Analysis perspective, Cycle Time is the average time for completion of a transaction (patient) in the whole process; Cycle Time includes average waiting time (patient waiting for a resource) and average processing time (patient working in an activity).

\subsubsection{Discrete-Event Methodology}

To define the diagram of activities, we adopted the Process Modeling and Notation (BPMN) language (Object Management Group 2011) which specifically illustrate business processes. BPMN consists of four basic categories of graphical elements: Flow Objects, Connecting Objects, Swimlanes and Artifacts. Flow Objects includes events, activities, and gateways. Events are something that "happens" in the flow of the process (i.e. Start, Intermediate, and End). Events are simply represented by circles with open centers to allow internal markers to differentiate them. Activities are rounded-corner rectangle representing single tasks or sub-processes. The representation of a sub-process is a small plus located in the bottom of the shape. Finally, gateways are elements that control the flow of execution of the process, represented by diamond shapes. Artifacts are graphical elements providing additional information about the process (data, text, inputs or outputs of activities). Connecting objects specified relationships among flow objects and they are represented as arcs. To group participants in the Process, the Pool container partitions a set of activities from others. A sub-partition within a Pool organizes activities in Lanes. The recent version of such standard language for business process modeling is BPMN 2.0 (Allweyer 2016).

In this work, we extend BPMN specifying for each element of the diagram quantitative parameters of the process, i.e. the duration of activities, the specific resources that the company allocates to the process and workload characteristics, as well as costs. To perform discrete-event simulation we adopt iGrafx Process2015, an environment suitable for process mapping and simulation modeling in business process management projects (iGrafx 2015). 


\subsubsection{Agent-Based Modeling}

Agent-based simulation is a style of modeling in which explicitly represent individuals (i.e. patients) and their interaction with each other and their environment (Wilensky and Rand 2015). Agent-Based Modeling $(\mathrm{ABM})$ is associated with object-oriented programming, which allows to represent real-world entities (people or cells) by objects. We have to specify information and features people have, as well as rules for how they interact with each other and their environment. We adopt the open-source programmable modeling environment NetLogo (Wilensky 1999), which is a popular modeling software, suitable for this kind of simulations. This tool is "by far the most professional platform in its appearance and documentation" (Railsback et al. 2006). The program manages thousands of agents (so called turtles) operating independently in a landscape made of static agents, building the background of the simulation (patches). Colors make possible to distinguish different areas of the environment corresponding to the activities of Emergency Department in which agents act.

\section{MODELING EMERGENCY SERVICES}

The representation of business processes provides an immediate understanding of the current organization, by mapping activities, resources and actors. Modeling implies deliberately chose and select main activities to represent reality, being useful as a baseline for improvement. We describe discrete-event model in section 4.1 and agent-based model in section 4.2. In each model we compute the duration of each activity by direct measurement, interviews to nurses and physicians. Each estimated value is modeled as a mathematical function with uniform or triangular distribution. Finally, for each activity we define the resources that work on it. For instance, triage nurses work on activities in "registration area".

\subsection{Discrete-event model}

Our discrete-event model includes 57 activities, 20 gateways as well as 12 delays in both main process and 11 sub-processes. Figure 2 describes the main diagram of the ED process having two starting points for the arrival of patients both by ambulance and by their own. Patients follow healthcare processes mostly consisting of visits, exams, advices. In particular, patients can be managed in observation areas (OBS) and exit from ED in different ways: dismission, transfer, death or abandon. The process validation involved medical staff as well as the actual manager of the hospital department. 


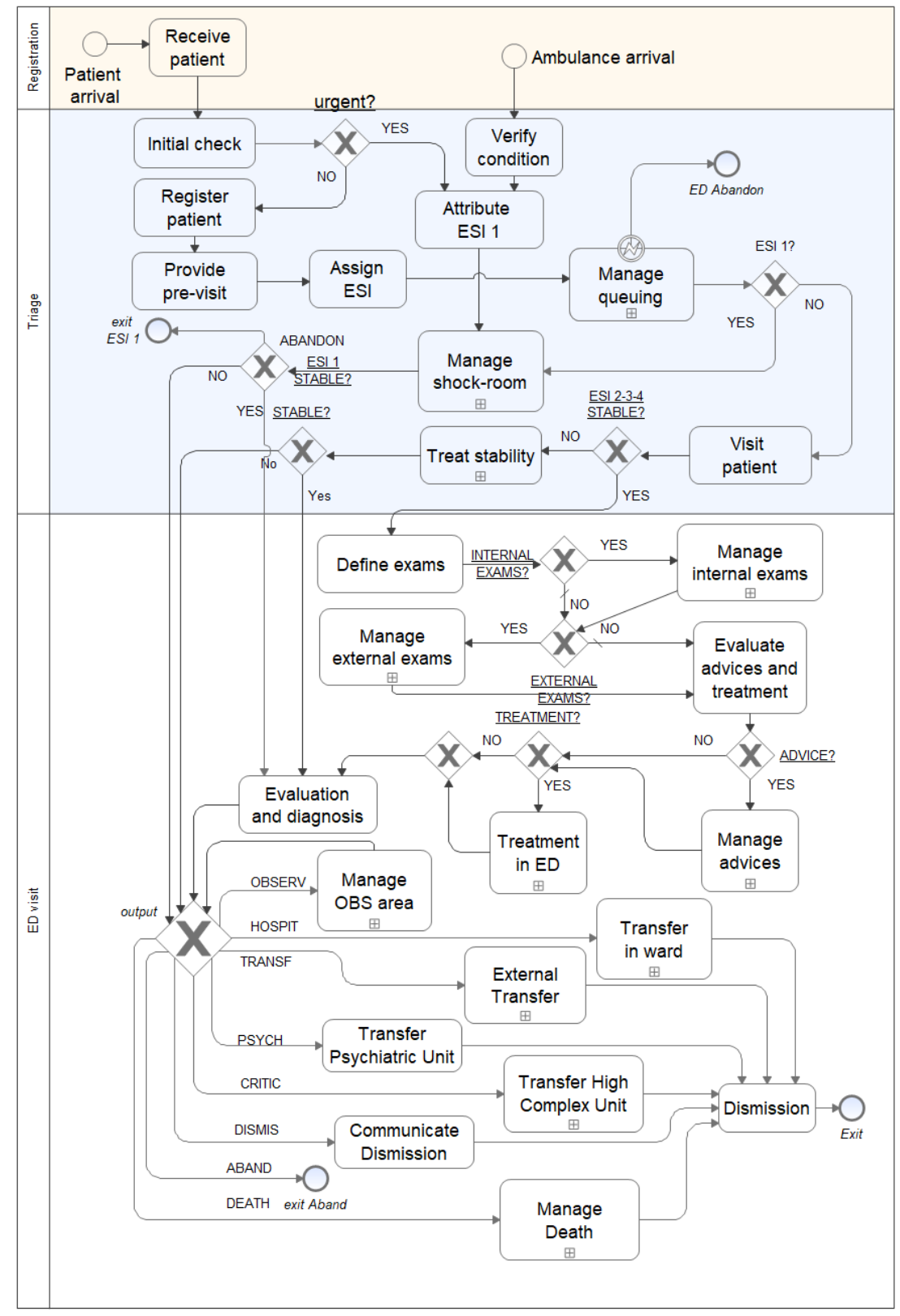

Figure 2: BPMN model of main diagram of Emergency Department

Most relevant gateways discriminate the flow accordingly to urgency levels, internal and external exams, as well as to address patients to their final destination. Patients can leave ED as modeled with five exits in our process. Sub-processes contain a specific set of activities which are related to a specific goal. For instance, the sub-process "Manage queuing" includes every activities related to verify conditions of patients as well as their aggravation in Triage area, before the first visit of a doctor, as detailed in Figure 3. 


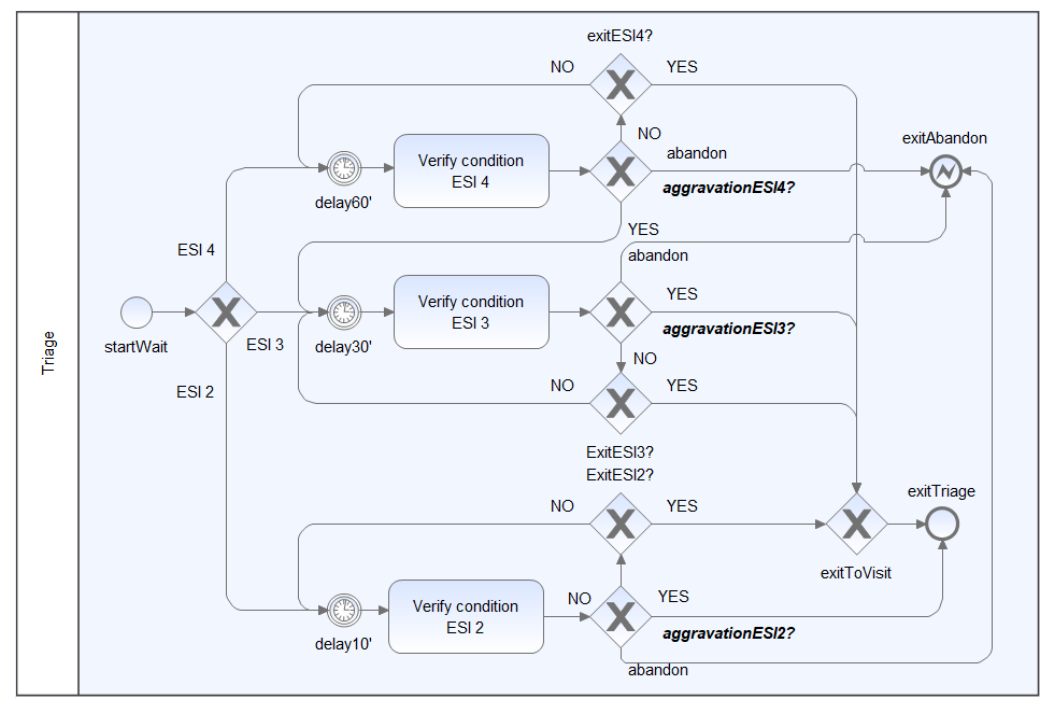

Figure 3: The sub-process diagram concerning manage queuing of not urgent patients in Triage

\subsection{Agent-based model}

The agent-based model in NetLogo defines agents (or turtles) acting in the environment (patches). In our simulation turtles are mainly patients and operators, moving in the Emergency Department (see Figure 4). We modeled patients as agents having several variables defined on the basis of the average values of the previous year (2017). Patients arrive in the simulated scenario following distribution based on real data. Operators are also agents having different working specialization (i.e. physician, nurses, social workers). Patients and operators are included into lists when they are free, while they move to join the corresponding activity (or position). Patients interact with patches and operators. Once patients arrive on an activity (for instance, the registration area), they have to wait the arrival of operators as defined in patch variables. Then, they work in the activity for the corresponding amount of time which is defined by secondary analysis as well as stored in a specific variable. This model was already better described in (Sulis and Di Leva 2017) and is available on OpenABM archive $^{2}$.

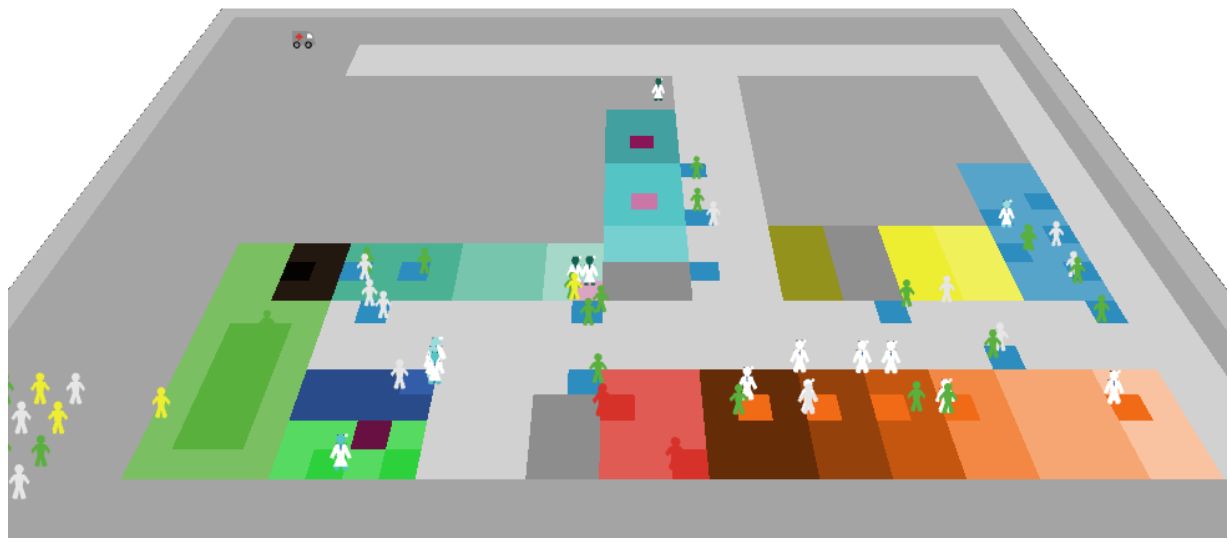

Figure 4: Agent-based model of emergency department in NetLogo.

\footnotetext{
${ }^{2}$ OpenABM is a repository for sharing resources and good practices for computational model-based science.
} 


\section{Simulation results}

The analysis of simulation output offers interesting suggestions about the impact of several scenarios, allowing managers to propose and compare different configurations of both resources and activities. We describe here the validation of our models, which is the preliminary step to propose variations of interest. Accordingly to ED managers, simulation results are generally reliable as well as quite close to real values. For instance, in our simulation models after one day and one night every queues are over. On the basis of the validation step described in section 5.1 and 5.2, managers performed scenario analysis to identify improvements, like decreasing and increasing the staff, or increasing the patients arrival, even changing the type of prevalent injuries.

\subsection{Discrete-event simulation}

Simulation output describes most demanding activities, distinguishing typical business process metrics like Cycle Time including Work Time and Wait Time. Figure 5 describes how to distinguish for each activity Average Working Time and Average Wait Time. Activities with longer duration are "visit patient" and "evaluation and diagnosis", while longer sub-processes are "Manage OBS area" and "External transfer". Considering Wait Time, we note that activities with higher delay are those involving physicians. This professional figure is the most requested and valuable in our ED.

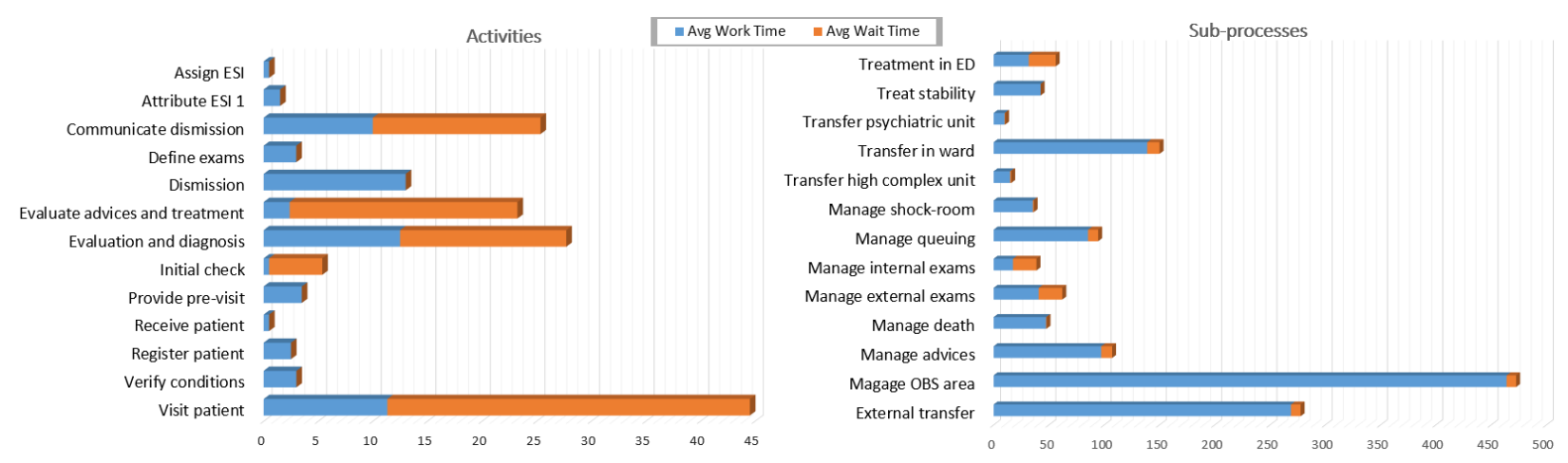

Figure 5: Working Times and Waiting Times of activities and suprocess (minutes).

The evaluation of the process by managers includes an exam of compared result, addressing main differences after June 4th disaster. By comparing the last output with the same day (one week before, May 28th), we obtained some suggestion to the impact of such an increment to our model. As Table 3 clearly states, most activities are faster due to the increment of resources, while the largest number of patients arriving in the ED had mainly repercussions on queue management. 
Table 3: Simulation results for main activities and sub-processes (times are computed in minutes).

\begin{tabular}{l|llll|llll} 
& \multicolumn{5}{|c|}{ May 28th } & \multicolumn{5}{c}{ June 4th } \\
\hline & $\mathrm{N}$ & Cycle & Work & Wait & $\mathrm{N}$ & Cycle & Work & Wait \\
\hline main activities & & & & & & & & \\
Evaluation and diagnosis & 209 & 37,36 & 12,74 & 24,63 & 295 & 14,64 & 12,75 & 1,88 \\
Initial check & 259 & 8,03 & 0,50 & 7,53 & 329 & 3,72 & 0,50 & 3,22 \\
Evaluate advices and treatments & 62 & 21,35 & 2,62 & 18,73 & 140 & 5,02 & 1,94 & 3,08 \\
Visit patient & 225 & 39,75 & 11,85 & 27,89 & 306 & 12,74 & 10,63 & 2,11 \\
Define exams & 62 & 3,03 & 3,03 & 0 & 138 & 2,97 & 2,97 & 0 \\
Dismission & 194 & 34,58 & 10,09 & 24,50 & 293 & 11,95 & 10,09 & 1,86 \\
sub-processes & & & & & & & & \\
Manage queuing & 258 & 101,35 & 88,11 & 13,24 & 327 & 127,89 & 116,56 & 11,34 \\
Manage Shock-Room & 1 & 38,92 & 38,92 & 0 & 7 & 30,85 & 30,85 & 0 \\
Manage advices & 27 & 135,35 & 125,22 & 10,13 & 44 & 87,89 & 86,62 & 1,28 \\
Manage external exams & 7 & 54,71 & 37,68 & 17,03 & 42 & 47,31 & 41,06 & 6,25 \\
Manage internal exams & 36 & 36,35 & 17,37 & 18,97 & 79 & 25,17 & 16,80 & 8,36
\end{tabular}

\subsection{Agent-based simulation}

The analysis of results for our agent-based simulation in NetLogo allows to consider another set of KPIs as well as to compare different configurations. In addition to May 28th and June 4th scenarios, we mention here simulation results for a setting which include the same increment of patients arrival as in the day of the crowd disaster (June 4th) but a decrease of staff (we called this scenario LessRes). In addition, we report results of a configuration where more patients arrived in the ED (250 instead of 188) while staff was increased as happened on June 4th (scenario MorePat). We consider here for demonstration purposes the following four scenarios:

- May 28th. This is a normal Sunday with typical staff and the arrival of 111 patients.

- June 4th. This is the day of the crowd disaster with increased staff and the arrival of 188 patients.

- LessRes. In this scenario we increased the staff of a half with respect to June 4th scenario, with the arrival of 188 patients.

- MorePat. This scenario includes the increased staff as in June 4th and the arrival of more patients (250 instead of 188).

Simulation results detailed in Table 4 clearly shows how Length of Stay slight increased in every new scenario after May 28th, while Door-To-Doctor-Time performs better. This is mainly due to the increment of physicians as well as other healthcare personnel. This is in accordance with medical impressions, which confirm how after emergency the increased staff worked more quickly in processing the large number of patients.

Table 4: Output simulations for our KPIs (Lenght-of-Stay and Door-To-Doctor-Time, both in minutes) for different settings: May 28th, June 4th, LessRes (as June 4th but with less personnel) and MorePat (as June 4th but with more patients arrival).

\begin{tabular}{l|cccc} 
& May 28th & June 4th & LessRes & MorePat \\
\hline LOS & 245 & 259 & 257 & 256 \\
DTDT & 34 & 29 & 40 & 32
\end{tabular}




\section{CONCLUSION AND FUTURE WORKS}

We test two different kinds of modeling and computational simulations as a way to address disaster and emergency management. In particular, we focus on the consequences of crowd disaster in an Hospital Emergency Department. We modeled activities, resources, and patients following Business Process Management perspective, by adopting standard language BPMN 2.0. In addition, we test an agent-based model as a way to address the same emergency issues.

Simulations results described by Key Performance Indicators demonstrated models validity. Output results confirm the usefulness of BPM approach for decision-making processes in disaster management. On the basis of such models, different strategies and scenarios can be tested to enable public services and medical preparedness sufficient to address a range of possible similar disasters.

In future works we plan to extend the current approach into two main directions. First, we would perform a real-time process-aware system to immediately detect critical issues regarding flow of patients, visualizing queues and bottlenecks, as well as performing scenario analysis with different configurations to provide real-time suggestion for decision-makers. We intend to adopt some extensions to our tools, i.e. NetLogo Web (available at: https://netlogoweb.org/launch). Second, we plan to introduce in our models the different costs of resources (staff and materials), in order to estimate the total expenditure for public services generated by various emergency settings.

\section{ACKNOWLEDGEMENTS}

We are grateful to Dr. Adriana Boccuzzi and Dr. Franco Ripa of the San Luigi Gonzaga hospital of Orbassano (Italy). This research was conducted within the project "CANP - CAsa Nel Parco" of Regione Piemonte funded by POR FESR PIEMONTE 2014-2020.

\section{REFERENCES}

Allweyer, T. 2016. BPMN 2.0: introduction to the standard for business process modeling. BoD-Books on Demand.

Amantea, I. A., A. D. Leva, and E. Sulis. 2018. "A Simulation-driven Approach in Risk-aware Business Process Management: A Case Study in Healthcare". In Proceedings of 8th International Conference on Simulation and Modeling Methodologies, Technologies and Applications - Volume 1: SIMULTECH,, 98-105. INSTICC: SciTePress.

Bellavita, C. 2008. "Changing homeland security: What is homeland security?". Homeland Security Affairs 4(2).

Birkland, T. A. 2009. "Disasters, Catastrophes, and Policy Failure in the Homeland Security Era1". Review of Policy Research 26(4):423-438.

Bulleit, W. M., and M. W. Drewek. 2005. "An agent-based model of terrorist activity". Proceedings of the North American Association for Computational Social and Organizational Science (NAACSOS 2005).

Catarci, T., M. de Leoni, A. Marrella, M. Mecella, B. Salvatore, G. Vetere, S. Dustdar, L. Juszczyk, A. Manzoor, and H.-L. Truong. 2008. "Pervasive software environments for supporting disaster responses". IEEE Internet Computing 12(1):26-37.

Chang, J. F. 2016. Business process management systems: strategy and implementation. CRC Press.

Di Leva, A., and E. Sulis. 2017. "Process analysis for a hospital Emergency Department". International Journal of Economics and Management Systems 2(1):34-41.

Di Leva, A., E. Sulis, and M. Vinai. 2017. "Business Process Analysis and Simulation: The Contact Center of a Public Health and Social Information Office". Intelligent Information Management 9(05):189-205.

Dumas, M., M. La Rosa, J. Mendling, and H. A. Reijers. 2013. Fundamentals of Business Process Management. Springer.

Gul, M., and A. F. Guneri. 2015. "A comprehensive review of emergency department simulation applications for normal and disaster conditions". Computers \& Industrial Engineering 83:327 - 344. 
Gunal, M. M. 2012. "A guide for building hospital simulation models". Health Systems 1(1):17-25.

Hale, T., and C. R. Moberg. 2005. "Improving supply chain disaster preparedness: A decision process for secure site location". International Journal of Physical Distribution \& Logistics Management 35(3):195207.

iGrafx 2015. iGrafxProcess 2015. http://www.igrafx.com.

Kahan, J. H. 2013. "What's in a name? The meaning of homeland security". Journal of Homeland Security Education 2:1.

Li, B., D. Sun, R. Zhu, and Z. Li. 2015. "Agent based modeling on organizational dynamics of terrorist network". Discrete Dynamics in Nature and Society 2015.

Mapar, J., K. Holtermann, J. Legary, K. Mahrous, K. Guzman, Z. Heath, C. J. John, S. A. Mier, S. Mueller, C. M. Pancerella et al. 2012. "The role of integrated modeling and simulation in disaster preparedness and emergency preparedness and response: the SUMMIT platform". In Homeland Security (HST), 2012 IEEE Conference on Technologies for, 117-122. IEEE.

Mustapha, K., H. Mcheick, and S. Mellouli. 2013. "Modeling and simulation agent-based of natural disaster complex systems". Procedia Computer Science 21:148-155.

Object Management Group, O. 2011. "Notation (BPMN) version 2.0". OMG Specification, Object Management Group:22-31.

Railsback, S. F., S. L. Lytinen, and S. K. Jackson. 2006. "Agent-based simulation platforms: Review and development recommendations". Simulation 82(9):609-623.

Shang, S., and P. B. Seddon. 2002. "Assessing and managing the benefits of enterprise systems: the business manager's perspective". Inf. systems journal 12(4):271-299.

Shendarkar, A., K. Vasudevan, S. Lee, and Y.-J. Son. 2008. "Crowd simulation for emergency response using BDI agents based on immersive virtual reality". Simulation Modelling Practice and Theory 16(9):1415 $-1429$.

Shimada, Y., T. Fuchino, T. Kitajima, and K. Takeda. 2012. "Disaster Management Based on Business Process Model Through the Plant Lifecycle". In Approaches to Managing Disaster, edited by J. Tiefenbacher, Chapter 2. Rijeka: InTech.

Skryabina, E., G. Reedy, R. Amlt, P. Jaye, and P. Riley. 2017. "What is the value of health emergency preparedness exercises? A scoping review study". International Journal of Disaster Risk Reduction 21:274 $-283$.

Sulis, E., and A. Di Leva. 2017. "An Agent-Based Model of a Business Process: The Use Case of a Hospital Emergency Department". In International Conference on Business Process Management, 124-132. Springer.

Sylves, R. 2014. Disaster policy and politics: Emergency management and homeland security. CQ Press.

Tan, L., M. Hu, and H. Lin. 2015. "Agent-based simulation of building evacuation: Combining human behavior with predictable spatial accessibility in a fire emergency". Information Sciences 295:53 - 66.

Tintinalli, J. et al. 2016. Tintinalli's emergency medicine: a comprehensive study guide. McGraw-Hill Education.

Tracy, M., M. Cerdá, and K. M. Keyes. 2018. “Agent-Based Modeling in Public Health: Current Applications and Future Directions". Annual review of public health (0).

Trkman, P. 2010. "The critical success factors of business process management". International journal of information management 30(2):125-134.

Van Der Aalst, W. M. 2013. "Business process management: a comprehensive survey". ISRN Software Engineering 2013.

Van Der Aalst, Wil MP and La Rosa, Marcello and Santoro, Flávia Maria 2016. "Business process management".

Van der Aalst, W. M., J. Nakatumba, A. Rozinat, and N. Russell. 2010. "Business process simulation". In Handbook on BPM 1, 313-338. Springer. 
Viswanadham, N. 2018. "Performance analysis and design of competitive business models". International Journal of Production Research 56(1-2):983-999.

Wilensky, U. 1999. "NetLogo". http://ccl.northwestern.edu/netlogo/, Center for Connected Learning and Computer-Based Modeling, Northwestern University, Evanston, IL.

Wilensky, U., and W. Rand. 2015. An introduction to agent-based modeling: modeling natural, social, and engineered complex systems with NetLogo. MIT Press.

\section{AUTHOR BIOGRAPHY}

EMILIO SULIS is a temporary research assistant in computer science at the Computer Science Department of the University of Turin, Italy. His current research interests are Data Analysis and Business Process Management by applying computational methods to study and simulate organization processes. He worked in Social Network Analysis and machine learning experiments. He also developed simulation projects with a two years grant. His formation includes high school diploma and $\mathrm{PhD}$ in computer science, and degree in sociology. His e-mail address is sulis@di.unito.it, and his web address is http://www.di.unito.it/ sulis. ANTONIO DI LEVA Dr. Antonio Di Leva was Associate Professor of Information Systems and Business Process Management at the University of Turin. Over the years he has worked in the field of databases, information systems and business process management. He is the author of over 100 articles in national and international journals and conference articles in these areas. He is the author and co-author of several books (in Italian) and co-editor of Computer-aided Database Design: the DATAID project, North-Holland, Amsterdam. He is currently involved in research on business process management and in simulation applied to the public health sector. His e-mail address is dileva@di.unito.it. 